\title{
Anxiety and depression in a sample of UK college students: a study of prevalence, comorbidity, and quality of life
}

Article

Accepted Version

Jenkins, P. E., Ducker, I., Gooding, R., James, M. and RutterEley, E. (2020) Anxiety and depression in a sample of UK college students: a study of prevalence, comorbidity, and quality of life. Journal of American College Health, 69 (8). pp. 813-819. ISSN 1940-3208 doi:

https://doi.org/10.1080/07448481.2019.1709474 Available at https://centaur.reading.ac.uk/88148/

It is advisable to refer to the publisher's version if you intend to cite from the work. See Guidance on citing.

To link to this article DOI: http://dx.doi.org/10.1080/07448481.2019.1709474

Publisher: Taylor \& Francis

All outputs in CentAUR are protected by Intellectual Property Rights law, including copyright law. Copyright and IPR is retained by the creators or other copyright holders. Terms and conditions for use of this material are defined in the End User Agreement. 


\section{CentAUR}

Central Archive at the University of Reading

Reading's research outputs online 
Anxiety and depression in a sample of UK college students: A study of prevalence, comorbidity, and quality of life

\begin{abstract}
Objective: This study sought to estimate the prevalence of depression and anxiety in UK college students and examine associations between mental health symptoms and quality of life (QoL). Associations between psychiatric comorbidity and degree of QoL impairment were also investigated.
\end{abstract}

Participants: Participants $(\mathrm{N}=286)$ were recruited from a UK university $(76.1 \% \leq 20$ yearsold; $86.8 \%$ female; $71.1 \%$ White).

Methods: Self-report measures of depression, anxiety, and QoL were completed online. Group differences and within-group associations were examined with Chi-square analyses, linear regressions, and ANOVAs.

Results: Prevalence rates were in line with global estimates and suggest female students are at elevated risk of mental health problems. Symptom severity and comorbidity were associated with greater QoL impairment.

Conclusions: Presence of depression, anxiety, or both was associated with QoL impairment. Findings develop understanding of the impact of mental health problems on QoL and could inform appropriate screening and effective interventions for student mental health.

Keywords: Depression; Anxiety; College students; Quality of life; Comorbidity

Word count: 2824 Words; Abstract: 150 Words 


\section{Introduction}

Individuals enrolled in higher education courses (hereafter referred to as "college students") represent a high-risk group for the experience of mental health problems and associated impairment. The majority of all lifetime cases of psychiatric disorders have developed by the age of $24,{ }^{1,2}$ and the prevalence of mental health problems in college populations is likely to be increasing. ${ }^{3,4}$ The presence of mental health problems is "clearly associated"5(p97) with poorer educational outcomes and, in the UK, $94 \%$ of higher education providers reported increased demand for counselling services over the most recent five years. ${ }^{4}$

Although several prevalence studies have been conducted, use of appropriate screening instruments has not been widespread. ${ }^{6}$ Furthermore, few studies have been carried out in the United Kingdom (UK), leading to unclear estimates of the scope and impact of mental health problems. Recent surveys have suggested that around one in five UK students experience mental health problems (e.g., $\left.{ }^{4}\right)$, in line with studies using standardized instruments. For example, Macaskill ${ }^{7}$ reported "psychiatric caseness" in $17.3 \%$ of undergraduates at a university in the north of England, and a study in Northern Ireland, conducted as part of the World Health Organisation (WHO) World Mental Health International College Student Initiative (see http://www.hcp.med.harvard.edu/wmh/college_student_survey.php), reported that nearly a quarter of first-year undergraduate students reported a major depressive episode or anxiety disorder in the year prior to starting university. ${ }^{8}$ Worldwide, it appears that around one-third of college students report current (i.e., within the last 12 months) mental health problems (e.g., see ${ }^{9,10}$ ).

Often overlooked in such studies is an estimate of comorbidity, where more than one psychiatric disorder is present simultaneously. Such comorbidity has been shown to be common in general population surveys ${ }^{1}$ (see also ${ }^{11}$ ) and is associated with greater 
impairment than one syndrome alone (e.g., ${ }^{12}$ ). In one of the few studies conducted in college samples, Eisenberg, Golberstein and Hunt ${ }^{13}$ concluded that the presence of both anxiety and depression was associated with poorer educational outcomes than depression alone. In addition, whilst more information is needed to establish prevalence rates in students, ${ }^{8}$ detailed data on the impact of these symptoms on functioning would also be illustrative (see ${ }^{14}$ ).

Quality of life (QoL) is defined by the WHO as an individual's "perception of their position in life in the context of the culture and value systems in which they live and in relation to

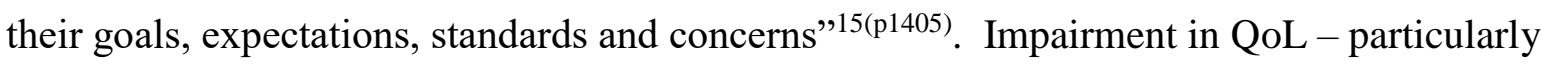
that related to illness, known as health-related quality of life (HRQoL) - is strongly associated with poorer health status and has therefore become an important metric within mental health. ${ }^{16}$ Roberts, Lenton, Keetharuth, and Brazier ${ }^{17}$ concluded that there is currently a "dearth of country specific data on the impact of mental health conditions,"(p1) and that this is particularly apparent in the UK. Estimating the impact of an illness (e.g., by measuring HRQoL) can provide an assessment of health status for an individual or sample, as well as enable standardised comparisons between the diverse health conditions likely to be seen in epidemiological studies. Further, studies of student mental health which include an assessment of HRQoL offer a unique perspective ${ }^{16}$ and can provide information to help improve the academic and social functioning of those identified as being at high risk. ${ }^{18}$ Results can also provide insights into help-seeking, given the relationship between individuals' reported HRQoL and odds of receiving treatment for a mental health problem. ${ }^{19}$

Studies of students support the relationship between mental health symptoms and impairment. For example, a number of studies have found that students who screened positive for depression scored lower on a number of HRQoL domains, ${ }^{20,21}$ with social functioning and close relationships particularly affected. ${ }^{14}$ However, past research has rarely 
considered the specific impact of comorbidity and often provided limited exploration of the association between mental health symptoms and HRQoL.

The objectives of the present study were to provide an estimate of the prevalence of depression and anxiety in students at a university in England and to examine associations between mental health symptoms and HRQoL. A further goal was to explore the association between psychiatric comorbidity and HRQoL impairment in this population.

\section{Materials and Methods}

\section{Participants and procedure}

Undergraduate and postgraduate students in the School of Psychology and Clinical Language Sciences (PCLS) at an urban university in the southeast of England were approached via student webmail lists or through a dedicated research participation scheme (where participation results in partial degree credit). Procedures for obtaining informed consent were included as part of the survey and participants were free to withhold answers or stop completing the survey at any time. Two-hundred and eighty-six participants completed the online survey between November 2018 and January 2019. Demographic questions were asked first, followed by the remaining measures of interest, which were presented in the order given below.

\section{Ethics approval}

The study was reviewed by the PCLS Ethics Committee and resources regarding mental health support groups were provided to all participants upon completion of the study. The study was performed in accordance with ethical standards as laid down in the 1964 Declaration of Helsinki and its later amendments. 


\section{Measures}

Participants were asked to indicate their age, the gender with which they identified, and their ethnicity. As part of a larger study, other measures were included but only those relevant to this study are reported here:

1. The PHQ-2 has been developed as a brief screening measure for depression. ${ }^{22}$ It comprises two items of the PHQ- $9,{ }^{23}$ concerning symptoms over the previous two weeks. Specifically, it asks how often participants have been bothered by: (1) "little interest or pleasure in doing things"; and (2) "feeling, down, depressed, or hopeless". Items are scored on a $0-3$ scale (ranging from "not at all" to "nearly every day"). A cutoff of $\geq 3$ has been suggested for diagnosis of any depressive disorder, with a specificity of $86 \% .^{24}$ The measure has demonstrated good psychometric properties in similar samples ${ }^{25}$ and the Spearman-Brown coefficient (a preferred alternative to Cronbach's for indicating the reliability of two-item scales) ${ }^{26}$ in the current study was 0.821.

2. The GAD-2 has been developed as a brief screening measure for anxiety. ${ }^{27}$ It comprises two items of the longer GAD- $7,{ }^{28}$ concerning symptoms over the previous two weeks. Scoring is the same as the PHQ- 2 and a cutoff of $\geq 3$ has been suggested for diagnosis of any anxiety disorder, with a specificity of $88 \% .{ }^{27}$ Like the PHQ-2, the GAD-2 has demonstrated good psychometric properties in US students. ${ }^{25}$ The Spearman-Brown coefficient was 0.863 .

3. The RAND 36-Item Health Survey $1.0(\mathrm{SF}-36)^{29,30}$ is a measure of QoL used for assessing the burden of different health states. Developed at RAND as part of the Medical Outcomes Study, ${ }^{29}$ it produces scores based on eight health concepts, specifically: Physical Functioning (PF), Role limitations due to Physical health problems (RP), Bodily Pain (BP), General Health (GH), Vitality (energy / fatigue) 
(VT), Social Functioning (SF), Role limitations due to Emotional problems (RE), and Mental Health (psychological distress and psychological well-being) (MH). All 36 items are scored individually and then converted to form a $0-100$ scale, with higher scores indicating better functioning. The SF-36 has been widely used as a measure of HRQoL and has demonstrated good psychometric properties across countries. ${ }^{31}$ Cronbach's $\alpha$ coefficients ranged from 0.74 (RP) to 0.89 (PF), indicating good internal consistency of the subscales.

\section{Statistical analyses}

Correlations between variables were examined using Spearman's rho $\left(r_{\mathrm{s}}\right)$, adjusted for nonnormality by reporting estimated bias-corrected (95\%) confidence intervals with 5000 replications. Chi-square analyses were used to investigate the prevalence of mental health symptoms by gender. Linear regressions were conducted to examine the associations of HRQoL with PHQ-2 and GAD-2 scores, in addition to sociodemographic variables. Examination of tolerance values and variance inflation factors suggested absence of multicollinearity issues. However, as most data were not normally distributed, groups were compared using Welch's W ANOVA with a post hoc Games-Howell test. Hypothesis testing was conducted at the 0.05 significance level (two-tailed). Based on a four-group ANOVA, a sample size of 280 is required to detect a medium-sized effect (e.g., ${ }^{32}$ ) with a power of $0.95 .{ }^{33}$

\section{Estimate of non-response}

Overall response rate is a poor index of response bias (e.g., $\left.{ }^{34}\right)$ and, although used in previous studies (e.g., ${ }^{35}$ ), comparison of respondents to non-respondents on demographic data (where this is known) is also not ideal. In the current study, it was not possible to use more sophisticated methods (e.g., the R-indicator) ${ }^{36}$ due to limited data on the wider 
(nonresponding) population. We therefore report demographic data to provide some information on the characteristics of responders and the wider population (see Table 1).

[Insert Table 1 here]

\section{Results}

\section{Sample description}

The final sample included data from 286 individuals. The mean (SD) age (of 285 who provided data) was 20.51 (4.19) years and the majority identified as female, with one individual not identifying with either male or female gender. Given overall student numbers in the School of PCLS, the survey response rate was $26.9 \%$ and the demographic profile was similar to the wider school (see Table 1). The majority of the sample described their ethnicity as White, with the remainder identifying as Asian (19.2\%), Black (3.5\%), Mixed (3.1\%), or Other (2.4\%). Mean (SD) PHQ-2 score was 2.06 (1.84) and 2.74 (1.92) for the GAD-2.

\section{Missing data}

Proportion of missing data was low and no question was omitted by more than seven individuals $(2.45 \%)$. The majority of individuals $(284 ; 99.30 \%)$ completed the PHQ-2 and $285(99.65 \%)$ the GAD-2. A smaller proportion $(n=269 ; 94.06 \%)$ completed the SF-36. Missing scores were calculated using recommended proration procedures. Following this, total missing data for the PHQ-2, GAD-2, and SF-36 was less than 0.5\%, with two-hundred and seventy-seven cases $(96.85 \%)$ providing complete data for analysis. Little's Missing 
Completely at Random test was not statistically significant $(\mathrm{p}=0.168)$, suggesting that data was missing at random. As such, we did not perform further missing data imputation.

\section{Creation of subgroups}

Correlations between variables of interest are shown in Table 2, suggesting strong associations between mental health problems and HRQoL. To investigate correlates of comorbidity, four groups were created based on responses to the GAD-2 and PHQ-2: no disorder $(\mathrm{n}=145 ; 51.1 \%)$; depression-only $(\mathrm{n}=19 ; 6.7 \%)$; anxiety-only $(\mathrm{n}=41 ; 14.4 \%)$; and both depression and anxiety $(n=79 ; 27.8 \%)$. Degree of illness severity was estimated in line with the procedure of Kroenke et al; ${ }^{32}$ specifically, PHQ-2 and GAD-2 scores were combined (also known as the PHQ-4) and classified as Normal (0-2; $\mathrm{n}=88)$, Mild (3-5; $\mathrm{n}=92)$, Moderate $(6-8 ; \mathrm{n}=53)$, and Severe $(9-12 ; \mathrm{n}=51)$.

[Insert Table 2 here]

\section{Prevalence of common mental health problems}

As shown in Table 3, 37.2\% of females and $16.7 \%$ of males screened positive for depression and $45.7 \%$ and $16.7 \%$ screened positive for an anxiety disorder. Further, $29.8 \%$ of females and $13.9 \%$ of males screened positive for both disorders. Females were more than four times as likely as males to screen positive for anxiety $(\mathrm{OR}=4.21,95 \% \mathrm{CIs}=1.69-10.47)$ and nearly three times as likely to screen positive for depression $(\mathrm{OR}=2.96,95 \%$ CIs $=1.19-$ 7.39). 


\section{Associations between mental health problems and quality of life}

Figure 1 shows the association between symptom severity (depression and anxiety) and SF36 scores. The change in SF-36 scores is shown as the difference between each severity group (Mild, Moderate, Severe) and the Normal group, used as a reference group (e.g., ${ }^{32}$ ). The effect size is calculated as the difference in means divided by the pooled SD, where values of $0.2,0.5$, and 0.8 represent small, medium, and large effect sizes, respectively. With the exception of $\mathrm{PF}$, the data suggest that increasing symptom severity is associated with greater impairment in HRQoL; these appear more pronounced in domains associated with mental (rather than physical) health.

[Insert Figure 1 here]

Results of regression analyses for all SF-36 subscales are shown in Table 4. PHQ-2 and GAD-2 did not uniquely predict variance in PF, although the overall model (including sociodemographic information) was significant, explaining $4.3 \%$ of the variance. PHQ-2 scores were uniquely associated with RP whereas GAD-2 scores were uniquely associated with BP. All other SF-36 subscales (GH, VT, SF, RE, MH) were strongly associated with both PHQ-2 and GAD-2 scores, which explained relatively large proportions of variance.

[Insert Table 4 here] 


\section{Psychiatric comorbidity and quality of life}

Table 5 shows SF-36 subscale scores for the total sample. In addition, scores are presented for four groups according to screening with the PHQ-2 and GAD-2: None (did not screen positive for either depression or anxiety); Depression (screened positive for depression); Anxiety (screened positive for anxiety); and Both (screened positive for both depression and anxiety).

[Insert Table 5 here]

Screening positive for at least two psychiatric disorders was consistently associated with significant impairment in HRQoL, with the exception of PF, which was equal across groups. Screening positive for one disorder was associated with levels of impairment between the other two groups in some domains $(\mathrm{SF}, \mathrm{MH})$, but statistically similar to the unaffected group in others $(\mathrm{RP}, \mathrm{BP})$.

\section{Discussion}

An emerging literature has begun to describe the extent and impact of mental health problems in college students. The current report builds on existing prevalence studies by investigating the association between these problems and quality of life. Overall rates of depression and anxiety in this UK sample are in line with US and global estimates (e.g., ${ }^{10}$ ), and also suggest that females are at greater risk of depression and, in particular, anxiety. This latter finding is in line with epidemiological studies suggesting recent increases in mental health problems in women aged $16-24$ (e.g., $\left.{ }^{38}\right)$, although studies of students have produced mixed findings 
regarding gender differences (e.g., see ${ }^{4,10}$ ). One limitation is that many studies, including the current one, focus on internalising, as opposed to externalizing, disorders. ${ }^{9}$

As predicted, the severity of symptoms of depression and anxiety was associated with greater HRQoL impairment, with the exception of physical functioning, and mental health impairment was more strongly associated with symptoms of depression and anxiety than impaired physical functioning. In line with previous suggestions (e.g., $\left.{ }^{13}\right)$, symptom severity appears to be progressively impairing across most areas of HRQoL. These findings (alongside the prevalence estimates) are particularly concerning given the suggestion that the severity of mental health problems in students is increasing. ${ }^{4}$

The third goal of the current study was to investigate the correlates of psychiatric comorbidity, finding prevalence rates similar to those in previous studies. For example, Bitsika and Sharpley ${ }^{39}$ reported that $33.2 \%$ of their sample of Australian university students screened positive for both anxiety and depression (27.8\% in the current sample) and Bruffaerts et $\mathrm{al}^{5}$ found that $36.1 \%$ of those who had one mental health problem also had another. Furthermore, findings of the currents study suggest that comorbidity is associated with greater impairments in HRQoL than one disorder alone (e.g., ${ }^{12,32}$ ), representing a particularly prevalent and disabling phenomenon which should be afforded consideration in approaches to student mental health and wellbeing.

The findings have implications for the provision of support for students with mental health problems and highlight the impairment that may result. While some symptoms were more strongly associated with specific areas of impairment than others, the findings suggest that comorbidity is not only common but particularly impairing. Taken together, results call for coordinated and effective interventions to reduce mental health problems in students, as well as appropriate screening to identify those in need., ${ }^{4,9}$ 
The current study had a number of strengths and limitations. The suite of measures has been widely used in similar samples and included a well-validated measure of HRQoL.

Confidence intervals are reported around estimates and the sample size was adequate for looking at group differences, although some subsamples were small and replication is indicated. Prevalence estimates are likely to be higher than other studies (e.g., $\left.{ }^{8,9}\right)$ due to the short time horizon of the PHQ-2 and GAD-2, which focused on two common mental health problems. Regarding gender differences, although females are generally the majority in such studies (e.g., ${ }^{9}$ ), the current sample demonstrated an over-representation and subsequent interpretations should consider this, as well as the comparatively young age of respondents. This may have been influenced by the sampling strategy, which was suboptimal, although does not necessarily compromise data quality. Nonetheless, a risk of bias remains and more detailed information on the sample might have allowed a more accurate estimate of nonresponse bias, although results compare favourably to similar studies in this area. ${ }^{4,6-11}$ Data on year of study (including undergraduate or postgraduate status), urbanicity, relationship status, and socio-economic status was not collected. These variables have been controlled for in previous studies ${ }^{14}$ or found to be associated with mental health symptoms (e.g., $\left.{ }^{11}\right)$, and may have provided additional information.

In summary, the findings add to a growing literature describing the prevalence and severity of mental health problems in university samples. The study also provides data on HRQoL, suggesting that the presence of anxiety, depression, or, particularly, both disorders was associated with significant impairments in self-reported health status. Future studies should consider changes over the course of study, given previous associations with year of study and mental health symptoms (e.g., ${ }^{40}$ ), and evaluate the support given to those with mental health problems in higher education. 
Declaration of interest: The authors do not declare any conflict of interest with respect to this publication.

Compliance with ethical standards: All participants provided informed consent prior to their inclusion in the study. The study was approved by the School of Psychology and Clinical Language Sciences Ethics Committee. 


\section{References}

1. Kessler RC, Berglund P, Demler O, Jin R, Merikangas KR, Walters EE. Lifetime prevalence and age-of-onset distributions of DSM-IV disorders in the National Comorbidity Survey Replication. Arch Gen Psychiatry. 2005;62:593-602. doi: 10.1001/archpsyc.62.6.593.

2. Kim-Cohen J, Caspi A, Moffitt TE, Harrington H-L, Milne BJ, Poulton R. Prior juvenile diagnoses in adults with mental disorder: developmental follow-back of a prospectivelongitudinal cohort. Arch Gen Psychiatry. 2003;60:709-717. doi:

10.1001/archpsyc.60.7.709

3. Hunt J, Eisenberg D. Mental health problems and help-seeking behavior among college students. J Adolesc Health. 2010;46:3-10. doi: 10.1016/j.jadohealth.2009.08.008

4. Thorley C. Not by degrees: Improving student mental health in the UK's Universities. Institute for Public Policy Research. 2017. http://www.ippr.org/research/publications/not-by-degrees. Accessed November 182019.

5. Bruffaerts R, Mortier P, Kiekens G, Auerbach R, Cuijpers P, Demyttenaere K, Green JG, Nock MK, Kessler RC. Mental health problems in college freshmen: prevalence and academic functioning. J Affect Disord. 2018;225:97-103. doi: 10.1016/j.jad.2017.07.044

6. Stallman HM. Psychological distress in university students: a comparison with general population data. Aust Psychol. 2010;45:249-257. doi: 10.1080/00050067.2010.482109

7. Macaskill A. The mental health of university students in the United Kingdom. Br J Guid Counc. 2013;41:426-441. doi: 10.1080/03069885.2012.743110

8. McLafferty M, Lapsley CR, Ennis E, Armour C, Murphy S, Bunting BP, Bjourson AJ, Murray EK, O'Neill SM. Mental health, behavioural problems and treatment seeking among students commencing university in Northern Ireland. PLoS One. 2017;12:e0188785. doi: 10.1371/journal.pone.0188785 
9. Auerbach RP, Mortier P, Bruffaerts R, et al. WHO World Mental Health Surveys international college student project: prevalence and distribution of mental disorders. J Abnorm Psychol. 2018;127:623-638. http://dx.doi.org/10.1037/abn0000362

10. Ibrahim AK, Kelly SJ, Adams CE, Glazebrook C. A systematic review of studies of depression prevalence in university students. J Psychiatr Res. 2013;47:391-400. doi: 10.1016/j.jpsychires.2012.11.015

11. Eisenberg D, Gollust SE, Golberstein E, Hefner JL. Prevalence and correlates of depression, anxiety, and suicidality among university students. Am J Orthopsychiatry. 2007;77:534-542. doi: 10.1037/0002-9432.77.4.534

12. Saris IMJ, Aghajani M, van der Werff SJA, van der Wee NJA, Penninx BWJH. Social functioning in patients with depressive and anxiety disorders. Acta Psychiatr Scand. 2017;136:352-361. doi: 10.1111/acps.12774

13. Eisenberg D, Golberstein E, Hunt JB. Mental health and academic success in college. B E J Econom Anal Policy. 2009;9. doi: 10.2202/1935-1682.2191

14. Alonso J, Liu Z, Evans-Lacko S, et al. Treatment gap for anxiety disorders is global: results of the World Mental Health Surveys in 21 countries. Depress Anxiety. 2018;35:195-208. doi: 10.1002/da.22711

15. WHOQOL Group. The World Health Organization quality of life assessment (WHOQOL): position paper from the World Health Organization. Soc Sci Med. 1995;41:1403-1409. doi: 10.1016/0277-9536(95)00112-K

16. Revicki DA, Kleinman L, Cella D. A history of health-related quality of life outcomes in psychiatry. Dialogues Clin Neurosci. 2014;16:127-135.

17. Roberts J, Lenton P, Keetharuth AD, Brazier J. Quality of life impact of mental health conditions in England: results from the adult psychiatric morbidity surveys. Health Qual Life Outcomes. 2014;12:6. doi: 10.1186/1477-7525-12-6 
18. Verger P, Guagliardo V, Gilbert F, Rouillon F, Kovess-Masfety V. Psychiatric disorders in students in six French universities: 12-month prevalence, comorbidity, impairment and help-seeking. Soc Psychiatry Psychiatr Epidemiol. 2010;45:189-199. doi: $10.1007 / \mathrm{s} 00127-009-0055-\mathrm{Z}$

19. Forrest LN, Smith AR, Swanson SA. Characteristics of seeking treatment among U.S. adolescents with eating disorders. Int J Eat Disord. 2017;50:826-833. doi: 10.1002/eat.22702

20. Paro HB, Morales NM, Silva CH, Rezende CH, Pinto RM, Morales RR, Mendonça TM, Prado MM. Health-related quality of life of medical students. Med Educ. 2010;44:227235. doi: 10.1111/j.1365-2923.2009.03587.x

21. Gan G-G, Hue Y-L. Anxiety, depression and quality of life of medical students in Malaysia. Med J Malaysia. 2019;74:57-61.

22. Kroenke K, Spitzer RL, Williams JB. The Patient Health Questionnaire-2: validity of a two-item depression screener. Med Care. 2003;41:1284-1292. doi: 10.1097/01.MLR.0000093487.78664.3C

23. Kroenke K, Spitzer RL, Williams JB. The PHQ-9: validity of a brief depression severity measure. J Gen Intern Med. 2001;16:606-613. doi: 10.1046/j.15251497.2001.016009606.x

24. Löwe B, Kroenke K, Gräfe K. Detecting and monitoring depression with a two-item questionnaire (PHQ-2). J Psychosom Res. 2005;58:163-171. doi: 10.1016/j.jpsychores.2004.09.006

25. Khubchandani J, Brey R, Kotecki J, Kleinfelder J, Anderson J. The psychometric properties of PHQ-4 depression and anxiety screening scale among college students. Arch Psychiatr Nurs. 2016;30:457-462. doi: 10.1016/j.apnu.2016.01.014 
26. Eisinga R, te Grotenhuis M, Pelzer B. The reliability of a two-item scale: Pearson, Cronbach, or Spearman-Brown? Int J Public Health. 2013;58:637-642. doi: $10.1007 / \mathrm{s} 00038-012-0416-3$

27. Kroenke K, Spitzer RL, Williams JB, Monahan PO, Löwe B. Anxiety disorders in primary care: prevalence, impairment, comorbidity, and detection. Ann Intern Med. 2007;146:317-325. doi: 10.7326/0003-4819-146-5-200703060-00004

28. Spitzer RL, Kroenke K, Williams JB, Löwe B. A brief measure for assessing generalized anxiety disorder: the GAD-7. Arch Intern Med. 2006;166:1092-1097. doi: 10.1001/archinte.166.10.1092

29. Hays RD, Sherbourne CD, Mazel RM. User's manual for the Medical Outcomes Study (MOS) core measures of health-related quality of life. Santa Monica, CA: RAND; 1995.

30. Ware JE, Sherbourne CD. The MOS 36-item short-form health survey (SF-36): I. conceptual framework and item selection. Med Care. 1992;30:473-483. doi: $10.1097 / 00005650-199206000-00002$

31. Ware JE Jr, Kosinski M, Gandek B, Aaronson NK, Apolone G, Bech P, et al. The factor structure of the SF-36 Health Survey in 10 countries: Results from the IQOLA Project. J Clin Epidemiol. 1998;51:1159-1165. doi: 10.1016/S0895-4356(98)00107-3

32. Kroenke K, Spitzer RL, Williams JBW, Löwe B. An ultra-brief screening scale for anxiety and depression: the PHQ-4. Psychosomatics. 2009;50:613-621. doi: 10.1016/S0033-3182(09)70864-3

33. Faul F, Erdfelder E, Lang A-G, Buchner A. G*Power 3: a flexible statistical power analysis program for the social, behavioral, and biomedical sciences. Behav Res Methods. 2007;39:175-191. doi: 10.3758/BF03193146

34. Peytcheva E, Groves RM. Using variation in response rates of demographic subgroups as evidence of nonresponse bias in survey estimates. J Off Stat. 2009;25:193-201. 
35. Barclay S, Todd C, Finlay I, Grande G, Wyatt P. Not another questionnaire! Maximizing the response rate, predicting non-response and assessing non-response bias in postal questionnaire studies of GPs. Fam Pract. 2002;19:105-111. doi: 10.1093/fampra/19.1.105

36. Schouten B, Cobben F, Bethlehem J. Indicators for the representativeness of survey response. Surv Methodol. 2009;35:101-113.

37. Higher Education Statistics Agency (HESA). Higher Education Student Statistics: UK, 2016/17 - Student numbers and characteristics. https://www.hesa.ac.uk/news/11-012018/sfr247-higher-education-student-statistics/numbers. Accessed April 25, 2019.

38. McManus S, Bebbington P, Jenkins R, Brugha T. Mental health and wellbeing in England: Adult Psychiatric Morbidity Survey 2014. Leeds, UK: NHS Digital; 2016.

39. Bitsika V, Sharpley CF. Comorbidity of anxiety-depression among Australian university students: implications for student counsellors. Br J Guid Counc. 2012;40:385-394. doi: $10.1080 / 03069885.2012 .701271$

40. Asante KO, Andoh-Arthur J. Prevalence and determinants of depressive symptoms among university students in Ghana. J Affect Disord. 2015;171:161-166. doi: 10.1016/j.jad.2014.09.025 
Table 1 Demographic characteristics of current sample, School of PCLS and UK students

\begin{tabular}{llll}
\hline & Current sample & School of PCLS & UK students ${ }^{\mathrm{a}}$ \\
\hline Female gender & $86.8 \%$ & Approximately $86 \%$ & $56.7 \%$ \\
Ethnicity - White & $71.7 \%$ & $72.8 \%$ & $77.3 \%$ \\
Age $\leq 20 \mathrm{y}$ & $76.1 \%$ & Approximately $70 \%$ & $41.0 \%$ \\
\hline
\end{tabular}

${ }^{a}$ Data from HESA ${ }^{37}$ 
Table 2 Correlations, Spearman's rho (95\% CIs). $N=277$

\begin{tabular}{|c|c|c|c|c|c|c|c|c|c|c|}
\hline Scale & PHQ-2 & GAD-2 & PHQ-4 & $\mathrm{PF}$ & $\mathrm{RP}$ & BP & GH & VT & SF & $\mathrm{RE}$ \\
\hline GAD-2 & $\begin{array}{l}0.631 \\
(0.550 \\
0.701)\end{array}$ & - & & & & & & & & \\
\hline PHQ-4 & $\begin{array}{l}0.895 \\
(0.868 \\
0.917)\end{array}$ & $\begin{array}{l}0.904 \\
(0.873, \\
0.927)\end{array}$ & - & & & & & & & \\
\hline PF & $\begin{array}{l}-0.197(- \\
0.308 \\
0.082)\end{array}$ & $\begin{array}{l}-0.192(- \\
0.307,- \\
0.071)\end{array}$ & $\begin{array}{l}-0.216(- \\
0.329,- \\
0.097)\end{array}$ & - & & & & & & \\
\hline $\mathrm{RP}$ & $\begin{array}{l}-0.333(- \\
0.433 \\
-0.225)\end{array}$ & $\begin{array}{l}-0.319(- \\
0.419,- \\
0.215)\end{array}$ & $\begin{array}{l}-0.361(- \\
0.455,- \\
0.262)\end{array}$ & $\begin{array}{l}0.259 \\
(0.141 \\
0.376)\end{array}$ & - & & & & & \\
\hline $\mathrm{BP}$ & $\begin{array}{l}-0.268(- \\
0.387 \\
-0.147)\end{array}$ & $\begin{array}{l}-0.271(- \\
0.385,- \\
0.154)\end{array}$ & $\begin{array}{l}-0.297(- \\
0.408,- \\
0.181)\end{array}$ & $\begin{array}{l}0.291 \\
(0.177, \\
0.398)\end{array}$ & $\begin{array}{l}0.243 \\
(0.124, \\
0.355)\end{array}$ & - & & & & \\
\hline $\mathrm{GH}$ & $\begin{array}{l}-0.409(- \\
0.508,- \\
0.302)\end{array}$ & $\begin{array}{l}-0.378(- \\
0.481,- \\
0.269)\end{array}$ & $\begin{array}{l}-0.438(- \\
0.535,- \\
0.337)\end{array}$ & $\begin{array}{l}0.460 \\
(0.355, \\
0.558)\end{array}$ & $\begin{array}{l}0.398 \\
(0.290, \\
0.496)\end{array}$ & $\begin{array}{l}0.267 \\
(0.158, \\
0.373)\end{array}$ & - & & & \\
\hline VT & $\begin{array}{l}-0.588(- \\
0.669,- \\
0.496)\end{array}$ & $\begin{array}{l}-0.514(- \\
0.607,- \\
0.416)\end{array}$ & $\begin{array}{l}-0.608(- \\
0.683,- \\
0.523)\end{array}$ & $\begin{array}{l}0.285 \\
(0.163, \\
0.401)\end{array}$ & $\begin{array}{l}0.299 \\
(0.184, \\
0.406)\end{array}$ & $\begin{array}{l}0.294 \\
(0.175, \\
0.406)\end{array}$ & $\begin{array}{l}0.473 \\
(0.373, \\
0.561)\end{array}$ & - & & \\
\hline SF & $\begin{array}{l}-0.659(- \\
0.727,- \\
0.580)\end{array}$ & $\begin{array}{l}-0.592(- \\
0.665,- \\
0.508)\end{array}$ & $\begin{array}{l}-0.686(- \\
0.749,- \\
0.610)\end{array}$ & $\begin{array}{l}0.256 \\
(0.142, \\
0.358) \\
\end{array}$ & $\begin{array}{l}0.371 \\
(0.263, \\
0.470)\end{array}$ & $\begin{array}{l}0.366 \\
(0.256, \\
0.469)\end{array}$ & $\begin{array}{l}0.350 \\
(0.234, \\
0.458) \\
\end{array}$ & $\begin{array}{l}0.476 \\
(0.378, \\
0.565)\end{array}$ & - & \\
\hline
\end{tabular}




\begin{tabular}{lllllllllll}
\hline RE & $-0.596(-$ & $-0.638(-$ & $-0.680(-$ & 0.239 & 0.324 & 0.171 & 0.363 & 0.509 & 0.591 & - \\
& $0.668,-$ & $0.709,-$ & $0.742,-$ & $(0.120$, & $(0.214$, & $(0.058$, & $(0.254$, & $(0.415$, & $(0.508$, \\
& $0.515)$ & $0.553)$ & $0.605)$ & $0.349)$ & $0.431)$ & $0.281)$ & $0.464)$ & $0.597)$ & $0.668)$ \\
& & & & & & & & & & \\
MH & $-0.768(-$ & $-0.709(-$ & $-0.818(-$ & 0.278 & 0.370 & 0.272 & 0.496 & 0.644 & 0.672 & 0.659 \\
& $0.816,-$ & $0.769,-$ & $0.857,-$ & $(0.161$, & $(0.262$, & $(0.160$, & $(0.389$, & $(0.560$, & $(0.589$, & $(0.586$, \\
& $0.709)$ & $0.639)$ & $0.769)$ & $0.388)$ & $0.471)$ & $0.377)$ & $0.593)$ & $0.719)$ & $0.739)$ & $0.724)$ \\
\hline
\end{tabular}

Note: all correlations significant at $p<0.01$ 
Table 3 Prevalence of common mental health problems by gender

\begin{tabular}{|c|c|c|c|c|c|}
\hline & \multicolumn{3}{|c|}{ Prevalence } & \multicolumn{2}{|c|}{ Test by gender (male / female) } \\
\hline & Females & Males & $\begin{array}{c}\text { Total } \\
\text { sample }\end{array}$ & Chi-square & $\begin{array}{l}\text { Odds ratio } \\
(95 \% \mathrm{CIs})\end{array}$ \\
\hline $\begin{array}{l}\text { Any depression } \\
\text { (PHQ-2) }\end{array}$ & $37.2 \%$ & $16.7 \%$ & $34.5 \%$ & $5.839, p=0.015$ & $\begin{array}{l}2.961(1.186, \\
7.388)\end{array}$ \\
\hline $\begin{array}{l}\text { Any anxiety disorder } \\
\text { (GAD-2) }\end{array}$ & $45.7 \%$ & $16.7 \%$ & $42.1 \%$ & $10.839, \mathrm{p}=0.001$ & $\begin{array}{l}4.205(1.689, \\
10.468)\end{array}$ \\
\hline $\begin{array}{l}\text { Both anxiety and } \\
\text { depression }\end{array}$ & $29.8 \%$ & $13.9 \%$ & $27.8 \%$ & $3.938, p=0.048$ & $\begin{array}{l}2.626(0.982, \\
7.024)\end{array}$ \\
\hline
\end{tabular}

Note: one individual did not identify with either a male or female gender and is excluded from this table. 
Table 4 Associations of symptoms of depression and anxiety with HRQoL

\begin{tabular}{lccc}
\hline $\begin{array}{l}\text { Dependent } \\
\text { variable }\end{array}$ & $\begin{array}{c}\text { \% variance } \\
\text { explained }\end{array}$ & \\
\hline SF-36 subscale & & PHQ-2 & GAD-2 \\
\hline PF & 3.0 & $-0.092(0.247)$ & $-0.106(0.188)$ \\
RP & 11.0 & $-0.229(0.003)$ & $-0.147(0.058)$ \\
BP & 9.1 & $-0.068(0.375)$ & $-0.265(0.001)$ \\
GH & 17.8 & $-0.273(<0.001)$ & $-0.205(0.006)$ \\
VT & 33.1 & $-0.411(<0.001)$ & $-0.237(<0.001)$ \\
SF & 45.8 & $-0.481(<0.001)$ & $-0.281(<0.001)$ \\
RE & 37.1 & $-0.280(<0.001)$ & $-0.411(<0.001)$ \\
MH & 63.8 & $-0.559(<0.001)$ & $-0.341(<0.001)$ \\
\hline
\end{tabular}

${ }^{a}$ Variance explained as change in $\mathrm{R}^{2}$ when adding PHQ-2 and GAD-2 to sociodemographic variables (age, gender, ethnicity). 
Anxiety and depression in UK students

Table 5 HRQoL in the total sample and groups according to responses on the PHQ-2 (Depression) and GAD-2 (Anxiety)

SF-36 Subscale, mean (SD)

\begin{tabular}{lllllllll} 
& PF & RP & BP & GH & VT & SF & RE & MH \\
\hline Total sample & 89.52 & 82.27 & 77.98 & 59.03 & 42.29 & 68.49 & 44.00 & 58.24 \\
& $(16.53)$ & $(28.22)$ & $(18.42)$ & $(20.17)$ & $(19.33)$ & $(23.88)$ & $(40.78)$ & $(20.34)$
\end{tabular}

Screening

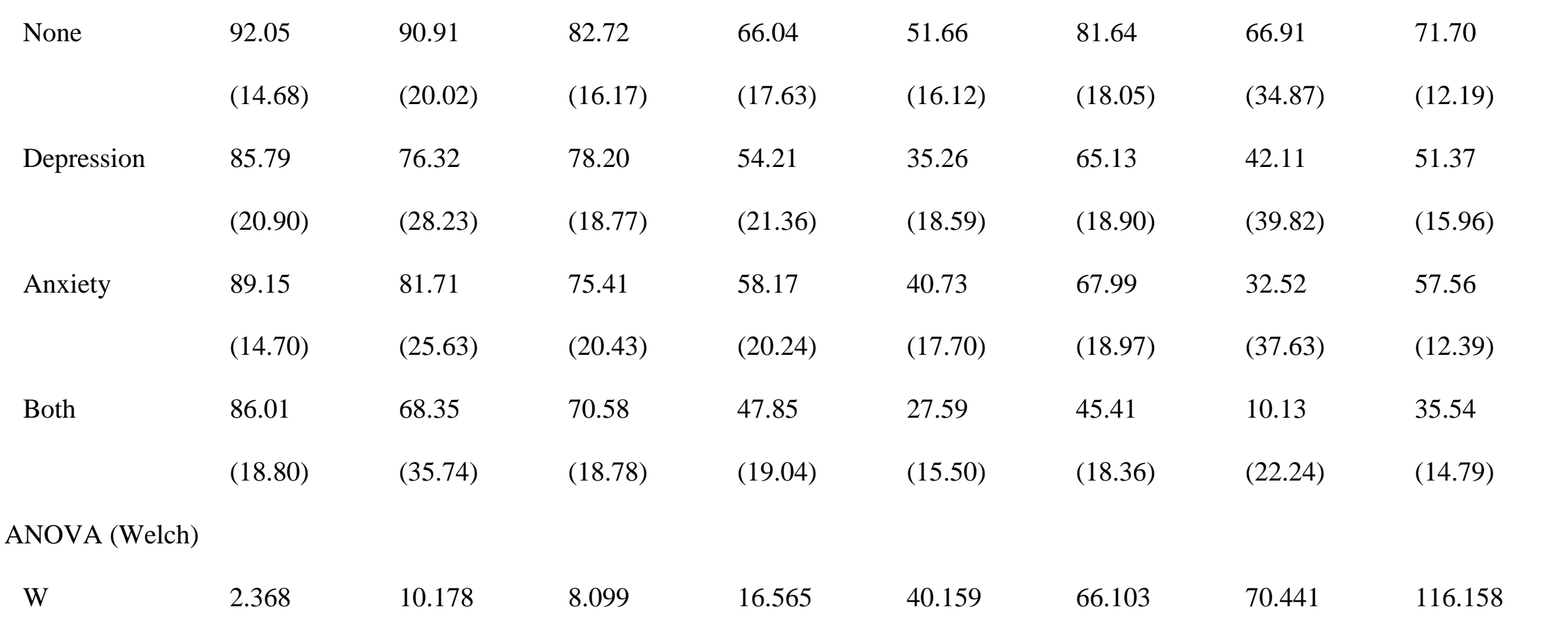


Anxiety and depression in UK students

\begin{tabular}{|c|c|c|c|c|c|c|c|c|}
\hline$p$-value & 0.079 & $<0.001$ & $<0.001$ & $<0.001$ & $<0.001$ & $<0.001$ & $<0.001$ & $<0.001$ \\
\hline Omega squared & 0.014 & 0.089 & 0.070 & 0.142 & 0.293 & 0.408 & 0.424 & 0.550 \\
\hline Post hoc (only & - & None $>$ Both & None $>$ Both & None $>$ & None > Dep; & None > Dep; & None > Anx; & None > Dep; \\
\hline significant & & & & Both; Anx > & None > Anx; & None > Anx; & None $>$ & None > Anx; \\
\hline differences & & & & Both & None > & None $>$ & Both; Dep > & None $>$ \\
\hline \multirow[t]{3}{*}{ shown) } & & & & & Both; Anx > & Both; Dep > & Both; Anx > & Both; Dep > \\
\hline & & & & & Both & Both; Anx > & Both & Both; Anx > \\
\hline & & & & & & Both & & Both \\
\hline
\end{tabular}


Anxiety and depression in UK students

Figure 1 Severity of depression and anxiety and HRQoL

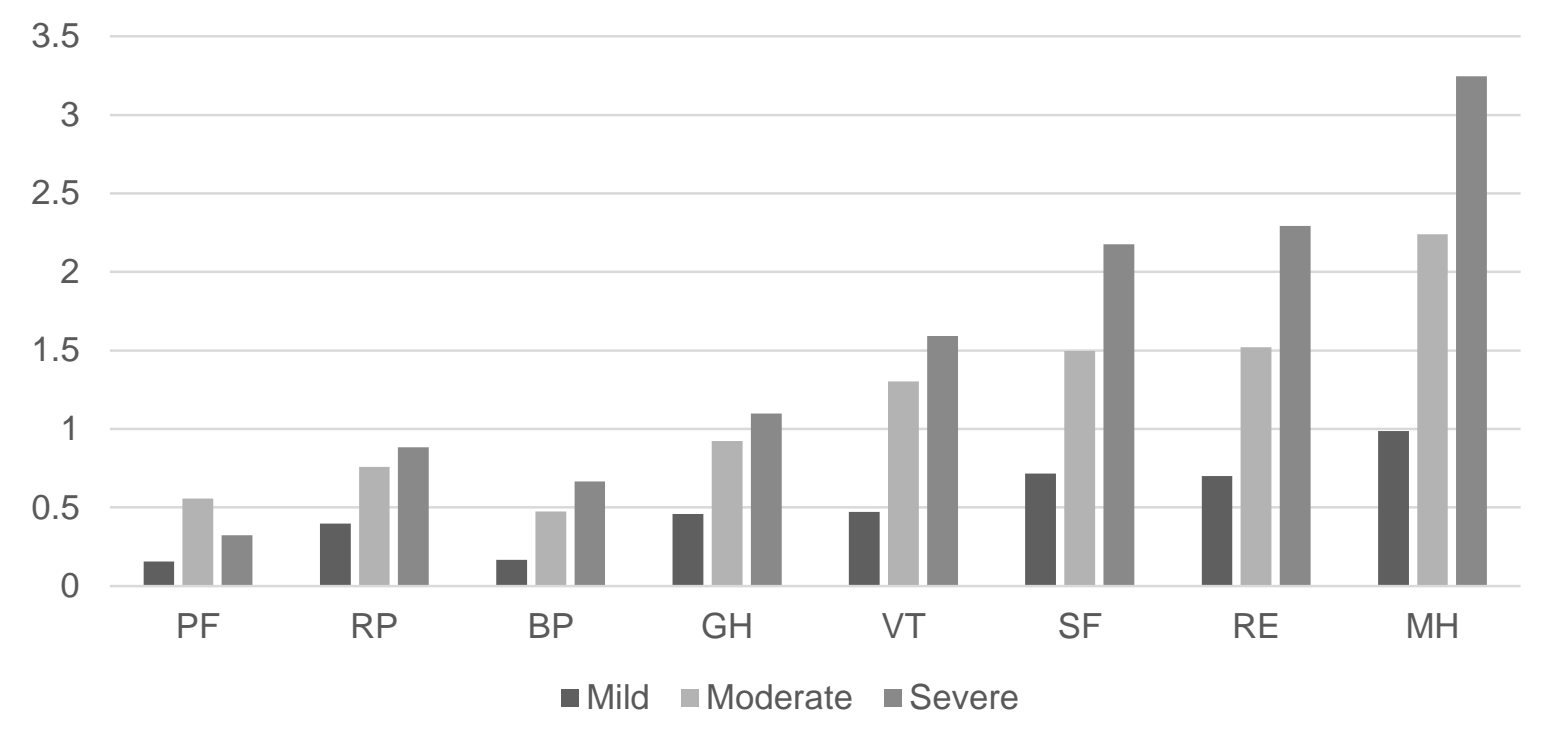

